\title{
Serodiagnostic studies on bovine leptospirosis in Beni-Suef Governorate W. H. Hassan
}

\author{
Department of Bacteriology, Mycology and Immunology, Faculty of Veterinary Medicine, \\ Beni-Suef University, Beni-Suef, Egypt
}

\begin{abstract}
The present study was carried out in dairy farms experiencing low reproductive efficiency. Blood samples were collected from 84 cattle and 16 buffaloes suffered from infertility problems for detection and titration of leptospiral antibodies using the microscopic agglutination test (MAT). Eleven standardized leptospira serovars were used as living antigens for this purpose. Sixteen (19.05\%) and $2(12.5 \%)$ samples were found positive for $L$. interrogans serovar Icterohaemorrhagiae for cattle and buffaloes respectively, with titers $\geq 1: 200$. Antibodies against L. interrogans serovar Pomona were detected in $8(9.52 \%)$ and $2(12.5 \%)$ in cattle and buffaloes respectively with titers $\geq 1: 400$. Two cattle $(2.38 \%)$ and two buffalo $(12.5 \%)$ samples were positive for $L$. interrogans serovar Djasiman. On the other hand, two cattle samples were positive for both L. interrogans serovar Icterohaemorrhagiae and $L$. interrogans serovar Pomona. Second serum samples were rechecked for seroconversion from each positively reacted animal with 3-4 weeks interval.
\end{abstract}

Leptospirosis is a worldwide zoonotic infection occurring in domestic and wild mammals. Many leptospira serovars have been described, but infections are usually produced by endemic serovars closely linked to ecological and environmental factors (Thiermann, 1984). Man and several animals are fully susceptible to infection with L. pomona, which is considered as the most common cause of leptospirosis among animals (Farid et al., 1982).

In cattle, the infection causes losses primarily because of its effects on reproductive performance; abortion, stillbirths, birth of reduced viability weak offspring as well as calf mortality and secondarily by decreased milk production. Because most of clinical manifestations of leptospirosis in bovines are non-specific, laboratory confirmed data are needed to determine the incidence of disease and associated risk factors before establishing an appropriate disease prevention strategy (Ismail et al., 2006). Leptospira interrogans infections had been reported as a cause of economic losses on dairy farms resulting in agalactia (Guitian, et al., 2001). Direct detection of these organisms by microscopic examination or culture is impractical due to the low success rate and the amount of time and labor required. Instead, leptospirosis is most often diagnosed

* Corresponding author.

Tel.: +20822329144; +20101546485 fax: +20822327982 .

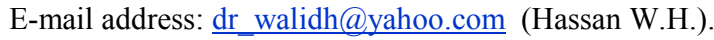

serologically with the microscopic agglutination test (Cole et al., 1973). The microscopic agglutination test is the "gold standard" serologic test to which other methods are compared (Isenberg, 2004). There are few studies concerning seroprevalence of leptospira infection in cattle and buffaloes in Egypt and there are inadequate data reporting the existence of leptospirosis in dairy cattle and buffaloes herds. Recent surveys in Europe recorded prevalences in randomly selected cattle of $10.4 \%$ (Espi, et al., 2000).

The present study aimed to determine the seroprevalence of Leptospira in cattle and buffaloes suffering from gynecological problems and/or abortion in Beni-Suef Governorate in a screening test against 11 leptospiral serovars. This will be followed by titration of the positively reacted sera and detection the seroconversion against leptospira in positive animals.

\section{Materials and Methods}

Animals. Blood samples were collected from 84, 2.5-5 years-old, cattle and 16, 4-8 years-old, buffaloes suffering from gynecological problems, infertility and/or abortion via vein puncture. Sera were separated and stored at $-20^{\circ} \mathrm{C}$ till processing. (The examined animals proved to be brucellosis negative for 3 successive tests).

Serum dilution. Five hundreds $\mu 1$ of phosphate buffer saline (PBS) were dispensed in Eppendorf 
Table (1): Leptospira serovars used for detection of antibodies by MAT.

\begin{tabular}{|c|c|c|c|c|c|}
\hline Serial & Genus & Species & Serovar & Serogroup & strain \\
\hline 1 & \multirow{11}{*}{ 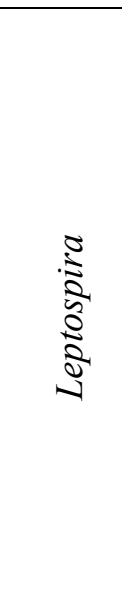 } & interrogans & Australis & Australis & Ballico \\
\hline 2 & & interrogans & Bratislava & Australis & $\begin{array}{c}\text { Jez } \\
\text { Bratislava }\end{array}$ \\
\hline 3 & & interrogans & Autumnalis & Autumnalis & Akiyami A \\
\hline 4 & & interrogans & Canicola & Canicola & Ruebush \\
\hline 5 & & interrogans & Grippotyphosa & Grippotyphosa & Moskva V \\
\hline 6 & & interrogans & Icterohaemorrhagiae & Icterohaemorrhagiae & RGA \\
\hline 7 & & interrogans & Pomona & Pomona & Pomona \\
\hline 8 & & interrogans & Pyrogenes & Pyrogenes & Salinen \\
\hline 9 & & interrogans & Wolffi & Sejroe & 3705 \\
\hline 10 & & interrogans & Djasiman & Djasiman & Djasiman \\
\hline 11 & & borgpetersenii & Javanica & Javanica & $\begin{array}{c}\text { Veldrat } \\
\text { Batavia } 46\end{array}$ \\
\hline
\end{tabular}

These strains were kindly supplied by Dr. M. E. Hatem head of the Microbiology Department, Faculty of Veterinary Medicine, Cairo University, Giza, Egypt.

tubes. To each tube, $10 \mu 1$ of serum sample was added, mixed well and incubated for $30 \mathrm{~min}$. at $56^{\circ} \mathrm{C}$ for decomplementation then stored at $4^{\circ} \mathrm{C}$ till use.

Antigen preparation. Ellinghausen medium modified by Johnson (EMJH), (Difco) (Ellinghausen and McCullough, 1965) and modified by (Johnson and Harris, 1967) was used for growing different leptospira serovars. Four to seven days-old broth cultures were used for preparation of antigens which were standardized to opacity approximately equal to McFarland opacity tube No. 0.5 (Baron et al., 1994).

Microscopic agglutination test (MAT). The standard MAT was performed for screening sera at fixed dilution using 96-wells ELISA plates by adding $50 \mu 1$ of PBS in each well starting from column 1 to 11 . From each diluted serum sample (1:50); $50 \mu 1$ were loaded to each row (from row 1-7 and row 8 contained $100 \mu \mathrm{l}$ PBS as negative control). Eleven serovars were used (Table 1). $100 \mu 1$ of live leptospira cell suspensions from each serovar was added to columns (1-11). The serum antigen mixtures were examined using a dark-field microscope at a magnification of $100 \mathrm{x}$ after incubation at room temperature $\left(25^{\circ} \mathrm{C}\right)$ for $2 \mathrm{~h}$.

Recording the microscopic agglutination test results (MAT). Strong positive reactions $(+++$ to ++++ ) were recorded and reactions $\leq+$ were recoded as negative. Weak positive reactions $(\geq$ + to $\leq++$ ) were subjected to confirmatory titration assay.
Titration of anti-leptospiral antibodies by MAT (Ismail et al., 2006). Antibody titration of positive serum samples was conducted after serial dilution of serum $(1: 50,1.100,1: 200$, 1:400,1:800, 1:1600, 1:3200 and 1:6400). The reported titers were calculated as the reciprocal of highest serum dilutions that agglutinate, at least $50 \%$ of the cells for each serovar. A positive reactive MAT result was determined by titers $\geq 1: 200$. Serovars included in the antigen panel used in the present work are shown in Table (1).

Seroconversion. Positive samples were rechecked for serovonversion after 3-4 weeks and MAT was performed for serially diluted serum samples as previously explained.

\section{Results}

A total of 28 out of $84(33.33 \%)$ and 6 out of $16(37.5 \%)$ examined cattle and buffaloes sera, respectively, had antibodies against one or more of the studied serovars by MAT (Table 2). Antibodies possessed against three leptospira serovars were detected in the present study; namely Icterohaemorrhagiae, Pomona and Djasiman. All examined cattle and buffaloes' sera were seronegative for other tested serovars.

As shown in Table (2), serovar Icterohaemorrhagiae represented the predominant detected serovar $(57.14 \%$ and $33.33 \%)$ followed by serovar Pomona $(28.58 \%$ and $33.33 \%$ ) and finally serovar Djasiman $(7.14 \%$ and $33.33 \%)$ were positive in cattle and buffaloes, respectively. Two cattle (7.14\%) were 
Table (2): Prevalence of Leptospira serovars in cattle and buffaloes from Beni-Suef, Egypt.

\begin{tabular}{|c|c|c|c|c|c|c|}
\hline \multirow[t]{2}{*}{ Serovar } & \multicolumn{2}{|c|}{$\begin{array}{l}\text { No. of positive } \\
\text { samples }\end{array}$} & \multicolumn{2}{|c|}{$\begin{array}{c}\text { Reactors } \\
(\%)\end{array}$} & \multicolumn{2}{|c|}{$\begin{array}{c}\text { Total } \\
(\%)\end{array}$} \\
\hline & Cattle & Buffaloes & Cattle & Buffaloes & Cattle & Buffaloes \\
\hline Icterohaemorrhagiae & 16 & 2 & 57.14 & 33.33 & 19.05 & 12.5 \\
\hline Pomona & 8 & 2 & 28.58 & 33.33 & 9.52 & 12.5 \\
\hline Djasiman & 2 & 2 & 7.14 & 33.33 & 2.38 & 12.5 \\
\hline $\begin{array}{l}\text { Icterohaemorrhagiae } \\
\text { Pomona }\end{array}$ & 2 & & 7.14 & 0.00 & 2.38 & 0.00 \\
\hline Total reactives & 28 & 6 & 100 & 100 & 33.33 & 37.5 \\
\hline Non-reactives & 56 & 10 & - & - & 66.67 & 62.5 \\
\hline Total & 84 & 16 & 100 & 100 & 100 & 100 \\
\hline
\end{tabular}

Table (3): Positive MAT samples against different Leptospira serovars at different dilutions.

\begin{tabular}{|c|c|c|c|c|c|c|c|c|c|c|}
\hline \multirow{3}{*}{ Leptospira serovar } & \multicolumn{8}{|c|}{ Titer } & \multirow{2}{*}{\multicolumn{2}{|c|}{$\begin{array}{l}\text { Total No. of } \\
\text { reactors }\end{array}$}} \\
\hline & \multicolumn{2}{|c|}{200} & \multicolumn{2}{|c|}{400} & \multicolumn{2}{|c|}{800} & \multicolumn{2}{|c|}{1600} & & \\
\hline & $\mathbf{C}$ & $\mathbf{B}$ & $\mathbf{C}$ & $\mathbf{B}$ & $\mathbf{C}$ & B & $\mathbf{C}$ & B & $\mathrm{C}$ & B \\
\hline Icterohaemorrhagiae & 2 & - & 8 & 2 & 6 & - & - & - & 16 & 2 \\
\hline Pomona & - & - & 4 & - & 4 & - & - & 2 & 8 & 2 \\
\hline Djasiman & - & - & - & - & 2 & 2 & - & - & 2 & 2 \\
\hline $\begin{array}{ll}* \text { Mixed } & \text { Icterohaemorrhagiae } \\
\text { Pomona }\end{array}$ & $* 2$ & & $* 2$ & & & & - & & 2 & - \\
\hline
\end{tabular}

*Only 2 cattle were positive for both serovars with different titers. $\mathrm{C}=$ Cattle $\quad \mathrm{B}=$ Buffaloes

positive for serovars Icterohaemorrhagiae and Pomona. As shown in table 2 and 3, the antibody titer range was 1:200-1:1600. In cattle, the highest number of reactors by MAT (titer $\geq$ $1: 200)$ was $16 \quad(19.05 \%)$ for serovar Icterohaemorrhagiae; at dilutions of 1:200, 1:400 and $1: 800,2,8$ and 6 samples were positive, respectively. On the other hand, 8 samples $(9.52 \%)$ were found positive for serovars Pomona; 4 and 4 at dilutions of 1:400 and 1:800. Concerning serovar Djasiman, 2 cases $(2.38 \%)$ were positive at dilution of 1:800. Mixed antibodies against serovars Icterohaemorrhagiae and Pomona were recorded in 2 cases $(2.38 \%)$ at 1:400 and 1:200, respectively.

In Buffaloes, 2 cases (12.5\%) were positive for serovars Icterohaemorrhagiae (1:400), 2 $(12.5 \%)$ were positive for serovars Pomona (1:1600) and 2 cases (12.5\%) were positive for serovar Djasiman (1:800).

\section{Discussion}

Bovine leptospirosis is associated with economic losses in cattle such as abortion (Faine et al., 2000), lowered fertility (Dhaliwal et al., 1996) and decreased milk production
(Lilenbaum and Santos, 1995). Infection in cattle has been classified into two major groups; one consisting of strains adapted to and carried by cattle, such as Hardjo, which are independent of lesion, and the second consists of accidental infection caused by strains that carried by other domestic and free-living animals which are dependent on farm management practices.

Limited studies on bovine leptospirosis were carried out in Egypt. Most of the previous studies on this disease reported seropositivities with very little isolations of leptospires. Maronpot and Barsoum (1972) recorded positive reactor buffaloes to different leptospira serotypes in Egypt at a percentage of $26.1 \%$. Out of these positive samples, $4(3.7 \%)$ reacted with $L$. icterohaemorrhagiae. In cattle samples, $34.5 \%$ showed seropositivities against different leptospiral serovars, including $L$. icterohaemorrhagiae, but none of them was positive against $L$. pomona. In the present work titers against $L$. interrogans serovar Icterohaemorrhagiae were recorded in sera of both cattle and buffaloes. The selection criteria of the studied farms were based only on convenience 
Table (4): Results of seroconversion on 34 different samples from cattle and buffaloes.

\begin{tabular}{|c|c|c|c|c|}
\hline \multirow{3}{*}{ Serovar } & \multicolumn{4}{|c|}{ Titers of positive cases* } \\
\hline & \multicolumn{2}{|c|}{ Cattle } & \multicolumn{2}{|c|}{ Buffaloes } \\
\hline & $1^{\text {st }}$ & $2^{\text {nd }}$ & $1^{\text {st }}$ & $2^{\text {nd }}$ \\
\hline \multirow{16}{*}{ L. interrogans serovar Icterohaemorrhagiae. } & $1: 200$ & $1: 200$ & $1: 400$ & $1: 800$ \\
\hline & $1: 200$ & $1: 1600$ & $1: 400$ & $1: 3200$ \\
\hline & $1: 400$ & $1: 3200$ & & \\
\hline & $1: 400$ & $1: 800$ & & \\
\hline & $1: 400$ & $1: 1600$ & & \\
\hline & $1: 400$ & $1: 3200$ & & \\
\hline & $1: 400$ & $1: 200$ & & \\
\hline & $1: 400$ & $1: 1600$ & & \\
\hline & $1: 400$ & $1: 800$ & & \\
\hline & $1: 400$ & $1: 3200$ & & \\
\hline & $1: 800$ & $1: 6400 * *$ & & \\
\hline & $1: 800$ & $1: 3200$ & & \\
\hline & $1: 800$ & $1: 3200$ & & \\
\hline & $1: 800$ & $1: 3200$ & & \\
\hline & $1: 800$ & $1: 1600$ & & \\
\hline & $1: 800$ & $1: 1600$ & & \\
\hline \multirow{8}{*}{ L. interrogans serovar Pomona } & $1: 400$ & $1: 3200$ & $1: 1600$ & $1: 1600$ \\
\hline & $1: 400$ & $1: 3200$ & $1: 1600$ & $1: 6400$ \\
\hline & $1: 400$ & $1: 1600$ & & \\
\hline & $1: 400$ & $1: 800$ & & \\
\hline & $1: 800$ & $1: 6400$ & & \\
\hline & $1: 800$ & $1: 6400$ & & \\
\hline & $1: 800$ & $1: 3200$ & & \\
\hline & $1: 800$ & $1: 3200$ & & \\
\hline \multirow{2}{*}{ L. interrogans serovar Djasiman } & $1: 800$ & $1: 6400$ & $1: 800$ & $1: 6400$ \\
\hline & 1:800 & $1: 1600$ & $1: 800$ & $1: 6400$ \\
\hline \multirow{2}{*}{$\begin{array}{l}\text { Mixed L. interrogans serovar } \\
\text { Icterohaemorrhagiae } \\
\text { and } L . \text { interrogans serovar Pomona }\end{array}$} & $\begin{array}{l}1: 400 \\
1: 200\end{array}$ & $\begin{array}{c}1: 3200 \\
1: 800\end{array}$ & & \\
\hline & $\begin{array}{l}1: 400 \\
1: 200\end{array}$ & $\begin{array}{l}1: 800 \\
1: 800\end{array}$ & & \\
\hline
\end{tabular}

*Seroconversion was considered positive when antibody titer increases $\geq 3$ fold.

** 1:800 dilution was considered diagnostic and serum antigen mixture did not exceed 1:6400 dilution.

$1^{\text {st }}=$ the first serum samples collect

$2^{\text {nd }}=$ the second serum samples collected 3-4 weeks later

and no attempt was made to isolate the agents due to shortage in culturing facilities. Eleven leptospiral serovars were used as living antigens for MAT for detection of leptospiral antibodies in examined cattle and buffaloe sera (Table 1). In Canada, cattle in artificial insemination centers were tested for a number of serovars, including Canicola, Icterohaemorrhagiae, Grippotyphosa, Hardjo, Pomona and Sejreo (Surujballi and Mallory, 2000). Results concerning the relative frequency of sero-reactors against different leptospiral serovars differ from those reported by other authors for cattle populations in other temperate regions. The seropositivity against Icterohaemorrhagiae as the predominant serovar in both cattle and buffalo in the present work may be attributed to the widespread of wild rats in the area from which animals were examined. Bovine leptospirosis is frequently encountered in dairy herds (Favero, et al., 2002). In Rio de 
Janeiro, Brazil, $68.4 \%$ of the herds were seropositive for leptospirosis, predominantly due to serovar hardjo (Lilenbaum and Santos, 1995).

Different study designs and threshold levels considered for the MAT could have contributed to the observed differences. Maronpot and Barsoum (1972) considered titers of 1:128 or greater against pathogenic leptospiras to be significant. In the current study, titers of 1:200 or greater were recorded as positive. However, in the second serological examination elevation of the titer 3-4 folds increase was considered as a definitive laboratory diagnosis for leptospirosis in animals under examination. On the other hand, titers of 1:800 were considered significant even if the increase in the second titer was less than two folds. According to the report of WHO (1982) titers of 1:800 or greater are indicative of an active leptospiral infection

Ismail, et al., (2006) detected serogroups, relatively similar to the early reports of animal infections in Egypt. Definitive laboratory diagnosis of leptospirosis requires detection of the organism in a clinical specimen or a 3 -fold or greater increase in MAT titer in the setting of an appropriate clinical syndrome.

Regarding 28 positive cattle samples, 5 samples were positive for L. interrogans serovar Icterohaemorrhagiae with a significant seroconversion indicating infection. In the meantime, 4 and 1 other samples reacted against L. interrogans serovar Pomona and Djasiman with significant seroconversions, respectively.

The magnitude and duration of the immune response induced by leptospiral infections is known to be very variable (Elder et al., 1985). Since the seroprevalence is influenced by both the frequency of new infections and the duration of the immune response induced, a longer duration of the immune response induced by $L$. interrogans serovars Icterohaemorrhagiae and Pomona infections could explain the relatively high seroprevalences found against these serovars. However, the prevalence results are consistent; the higher seroprevalences against $L$. interrogans serovars Icterohaemorrhagiae and Pomona were associated with a higher probability of seroconversion against these serovars in the farms where cows and buffaloes were followed-up. This result is in agreement with the finding of Guitian et al., (2001).

In the present study positive animals were surveyed for leptospiral antibodies twice with 34 weeks interval to detect seroconversion because interpretation of leptospira serological results is complicated by a number of factors. These factors include cross-reactivity of antibodies and the lack of consensus about what antibody titers are indicative of active infection in non vaccinated animals. However, in general, the infecting serovars are assumed to be the serovars to which those animals develop the highest titer (Bolin, 2003). Seroconversion in cattle samples revealed that 5 samples for serovar Icterohaemorrhagiae, 4 for serovar Pomona and one for serovar Djasiman, all had 3 folds increase in antibody titers. One of the mixed Icterohaemorrhagiae and Pomona samples showed seroconversion for serovar Icterohaemorrhagiae. Regarding the 6 positive buffalo samples, one showed seroconversion for serovar Icterohaemorrhagiae and two for Djasiman.

\section{Conclusion}

Infection in examined cattle and buffaloes may be accidental and caused by strains carried by other domestic and free-living animals which are dependent on farm management practices. Leptospira interrogans serovar Icterohaemorrhagiae and Pomona were the predominant serovars in both cattle and buffalo in the present work and this may be attributed to the widespread of wild rats in the area from which animals were under examination. The presence of high titers against these two serovars in sera of cattle and buffaloes represents a significant public health hazard for man and a possible cause of great economic losses in animals.

\section{Acknowledgment}

I would like to express my deepest gratitude to Prof. Dr. Mahmoud Essam Hatem, professor and head of the Microbiology Department, Faculty of Veterinary Medicine, Cairo University, Egypt, for his kind supplying of the reference strains used, his valuable advice and guidance throughout the course of this work. Without him the entailed work would have been more difficult.

\section{References}

Baron, E. J.; Peterson, L. R. and Finegold, S. M. (1994): Bailey and Scott's Diagnostic Microbiology $9^{\text {th }}$ ed. MosbyYear Book, Inc. pp. 169-171.

Bolin, C. A. (2003): Diagnosis and control of bovine leptospirosis proceedings of the $6^{\text {th }}$ Western Dairy Management Conference. March 12-14

Cole, J. R.; Sulzer, C. R and Pursell, A. R. (1973): Improved microtechnique for the leptospiral microscopic agglutination test. Appl. Microbiol., 25: 976-980.

Dhaliwal, G. S.; Murray, R. D. and Ellis, W. A. (1996): Reproductive performance of dairy herds infected with Leptospiral interrogans serovars hardjo relative to the year of diagnosis. Vet. Rec., 138: 272-276. 
Elder, J. K.; Pepper, P. M.; Hill, M. W. M. and Ward, W. H. (1985): The significance of leptospiral titers associated with bovine abortion. Aust. Vet. J., 62: 258-262. Ellinghausen, H. C. and McCullough, W. G. (1965): Nutrition of Leptospira pomona and growth of 13 other serotypes. A serum free medium employing oleic albumin complex. Am. J. Vet. Res., 26: 39-51.

Espi, A.; Prieto, J. M. and Alvarez, M. (2000): Serological prevalence to six Leptospira serovars in cattle in Asturias (Northern Spain). Epidemiol. Infect., 124: 599602.

Faine, S.; Adler, P.; Bolin, C., Perolat, P. (2000): Leptospira and leptospirosis $2^{\text {nd }}$ ed. Med Sci., Melbourne, Australia.

Farid, A.; Hatem, M. E. and Refai, M. (1982): Leptosirosis in domestic animals in Egypt. Zagazig Vet. J., 6: 133-143.

Favero, A. C. M., Pinheiro, S. R., Vasconcellos, S. A., Morais, Z. M., Ferreira, F., and Ferreira Neto, J. S. (2002): Serovares de Leptospiras prevalentes em exames sorologicos de bubalinos, bovinos, caprinos, equinos, suinos e caes de diversos Estados brasileiros. Ciencia Rural 32.

Guitian, F. J.; Garcia-Pena, F. J.; Oliveira, J; Sanjuan, M. L. and Yus, E. (2001): Serological study of the frequency of leptospiral infections among dairy cows in farms with suboptimal reproductive efficiency in Galicia, Spain. J. Vet. Microbiol., 80: 275-284.

Isenberg, D. H. (2004): Leptospira culture. In Clinical
Microbiology Procedures Handbook, $2^{\text {nd }}$ ed. Vol. 1 ASM press, Washington, D.C.

Ismail, T. F.; Wasfy, M. O; Abdul-Rahman, B.; Murray, C. K.; Hospenthal, D. R.; Abdel-Fadeel, M.; AbdelMaksoud, M.; Samir, A.; Hatem, M. E.; Klena, J.; Pimentel, G.; El-Sayed, N. and Hajjeh, R. (2006): Retrospective seroservey of Leptospirosis among patients with acute febrile illness and hepatitis in Egypt. Am. J. Trop. Med. Hyg., 75 (6): 1085-1089.

Johnson, R. C. and Harris, V. C. (1967): Differentiation of pathogenic and saprophytic leptospires. I. Growth at low temperature. J. Bacteriol., 94: 27-31.

Lilenbaum, W. and Santos, M. R. C. (1995): Leptospirosis on animal reproduction. III. The role of serovar hardjo on bovine leptospirosis in Rio de Janeiro, Brazil. Revista Latinoamericana de Microbiologia 37: 8792.

Maronpot, R. R. and Barsoum, I. S. (1972): Leptospiral microscopic agglutinating antibodies in sera of man and domestic animals in Egypt. Am. J. Trop. Med. Hyg., 21 (4): 467-472.

Surujballi, O. and Mallory, M. (2000): Competitive enzyme-linked Immunosorbent assay or detection of Leptospira interrogans serovar Pomona antibodies in bovine sera. Clin. Diag. Lab. Immunol., (8) 1: 40-43.

Thiermann, A. B. (1984): Leptospirosis: Current developments and trends. JAVMA, 184: 722-725.

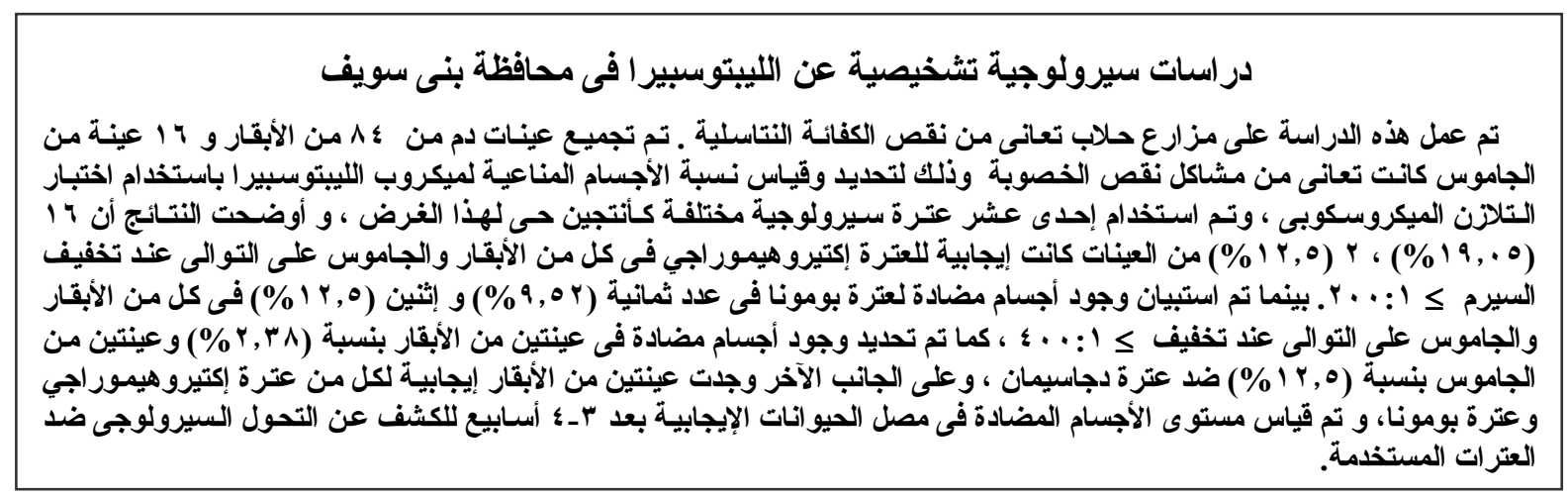

